first floor of this will be used for the first-year undergraduate teaching laboratory. The total useful floor space in the old and new building will be somewhat over $60,000 \mathrm{sq}$. ft. The number of physics students in all years has been nearly 1,000 in the session 1961-62; future numbers will depend on the University's policy about limitation.
The architect of the building was Mr. John MacGeagh, the principal contractors Messrs. F. B. McKee and Co., Ltd., and the engineering consultants Messrs. Oscar Faber and Partners. The Department's interests have been attended to by Dr. R. H. Sloane, reader in physics. The total cost has been about $£ 800,000$.

\title{
EXPERIMENTAL TAXONOMY
}

$\mathrm{T}$ HE annual symposium of the group for experimental taxonomy of the Linnean Society of London was held on March 2, at the Society's rooms in London. After a brief introduction from Prof. D. H. Valentine, the meeting began with a paper by Dr. D. M. Moore (University of Leicester), on "Speciation within Chilean Clarkias". The annual genus Clarkia contains somo 34 species in western North America, and a series of forms from central Chile and adjacent regions of Argentina which are presently included under $C$. tenella (Cav.) Lewis and Lewis. C. tenella is tetraploid and has been shown to be closely related to $C$. davyi of coastal California by Raven and Lewis, who suggested that South American plants resulted from trans-equatorial long-distance dispersal in late Pliocene or more recent time. Data were presented to illustrate the pattern of variation within the Chilean species of Clarkia and its correlation with the breeding system. It was suggested that the ancestral introduction was close to the largeflowered outcrosser, with $n=17$, which occurs in southern central Chile; and a scheme was outlined to suggest the derivation of the other South American forms from this type. Some populations of outcrossers, separated from the others and representing the southermmost occurrence of the genus, have lost a pair of chromosomes but are morphologically identical with the 17-chromosome form. Most differentiation was shown to be associated with the change to autogamy, which generally involves no change of chromosome number. Self-pollinated forms have the stamens and style of equal length; anthers and style mature simultaneously and are in close contact. The most widespread form has small flowers, is markedly self-pollinated and shows a whole range of biotypes usually differing slightly from one another, though occasional more extreme deviants are found. Populations intermediate morphologically between these small-flowered self-pollinaters and the outcrosser are facultatively outcrossing, though primarily self-pollinated, suggesting a gradual change to autogamy. Another entity sympatric with, but temporally quite isolated from, the outcrosser has acquired self-pollination without other marked morphological change. In only one case do selfpollinating plants show a different chromosome number, $2 n=28$; they are also remarkable for their yellow flowers, which are very rare in the genus. This scheme was discussed in relation to the frequent independent origin of self-pollinating from outcrossing forms within Clarkia.

The second paper, by Dr. A. J. S. Davies (Chester Beatty Institute), was entitled "A Cytogenetic Study of 28 Species of the Genus Lathyrus". "The genus as a whole contrains some 110 species oceupying marginal and open habitats. Many morphological characters are used in the comparison of phenotypes in the traditional taxonomy of the group, and evolutionary trends in some of these can be postulated. The bracts at the base of the pedicel provide a useful indication of whether a spocies is specialized or not: there is a trend from long leafy bracts, to shorter, to a state where they are represented by a tuft of hairs. The genus is predominantly diploid $(2 n=14)$ and gross chromosomal changes have probably not played a large part in its evolution. It is thought that there has been a tendency for chromosome-length to decrease and for the karyotype to become more asymmetrical, and this trend is associated with a decrease in plant size. Attempts have been made to cross fourteen of the annual species; and it has been shown that embryo abortion is the main barrier to interspecific hybridization. Hybrid plants have, however, been raised from four combinations of species. One of these was taken to the $F_{2}$ generation, and it was shown that at least four major gene loci are common to the parental species. Two of these genes, however, were modified in their expression in the $F_{2}$, indicating differences in the genetic background of the two species involved.

Dr. C. D. K. Cook (University of Liverpool) gave the next paper on "Variation in Ranunculus subg. Batrachium". He noted that the number of taxa recognized from the time of Linnæus to the present day ranged from 1 to 108 ; the number of now names per decade follows a normal curve of distribution. Much of the confusion in the group is due to the wide range of phenotypic plasticity shown by the species and the inability of workers to distinguish it, in the herbarium, from genotypic variation. In cultivation, a grcat deal of variation, both genotypic and phenotypic, is revealed. Thus, the achene number in both British (Isle of Wight) and Finnish (Helsinki) topodemes of $R$. baudotii varied from 10 to 60 ; but under experimental conditions, they differed in the average number of achenes produced in still and flowing water. Their total plasticity-range was, however, the same. and they are best regarded as two parts of a cline, with different ecological preferences. Extreme phenotypes occasionally become genetically fixed; an example is provided by plants of the alpine state of $R$. trichophyllus, some of which retain their original shape when eultivated in lowland conditions, and some of which revert to normal. The transition between capillary and laminar leaves in the group is always abrupt and is affected by length of day and temperature, but it is primarily undor genetic control. Many hybrids are known. Some are infertile but very persistent, for cxample, some pentaploids in the fluitans group. Other species form fertilo hybrids which are often unstable and unlikely to persist, but great variability in the $\mathrm{F}_{2} \mathrm{~s}$ has been demonstrated, and some of these, which differ greatly from their parents, may occasionally be able to invade new habitats.

Dr. A. J. F. Smith (University College, Swansea) then gave a paper on "Variation in Melampyrum 
pratense". This semi-parasitic species is difficult to raise from seed, but experiments have shown that it will grow on a variety of woody plants, such as species of Betula, Calluna and Rubus. It is very variable, 28 intraspecific taxa having been described, and much of this variation follows geographical trends in the British Isles. Plants become shorter in the north, and this is correlated with a reduction in the number of leaves and branches. The leaves also become shorter in the north and west. Antherlength is 20-30 per cent shorter in Northern Ireland than elsewhere. Superimposed on this clinal and geographical variation is ecological variation; the leaf width/length ratio divides the populations into those of calcareous and acid habitats, but the distinetion is not clear-cut. Population samples were grouped according to habitat types and an analysis was made of the variation, using 8 vegetative and 3 floral characters, all of them quantitative. This showed that there was random distribution of genes or gene combination in the small isolated populations in which the plant occurs, and that similar groups of characters occurred in similar habitats. Some populations had cleistogamous flowers and were effectively inbreeding units. The variation pattern in certain morphological characters was, however, markedly different from that observed on the Continent.

Dr. J. K. Morton (Birkbeck College) gave the final paper on "Introgression in West African Eulophia Orchids". Two species, $E$. cristata and $E$. millsoni, were studied in the Accra coastal plains where their hybridization is associated with the disturbance caused by peasant agriculture, although their ocological preferences are different. Populations were analysed in order to discover the extent and direction of the apparent introgressive hybridization which was taking place. Ten characters associated with the structure of the flower and inflorescence were scored, such as height of inflorescence, number of flowers, and angle of lateral lobes of the lip to the horizontal; the introgression was demonstrated by pictorialized scatter diagrams and histograms. A remarkable feature which emerged was the unilateral gene-flow, back-crossing to the $E$. millsoni parent being frequent while none to $E$. cristata was detected. The introgression affected the biology of the populations, the millsoni hybrids extending the range of the species. Vegetative features were not included in the introgression studies since the leaves appeared 2-3 months later than the flowers.

The general discussion was opened by Dr. V. H. Heywood (University of Liverpool), who commented that the day's papers illustrated the tendency of botanists to emphasize breeding systems and dispersal mechanisms in consideration of speciation and adaptation, while zoologists place greater emphasis on phenotypic plasticity. He suggested that botanists should pay greater attention to the adaptive role of plasticity: they should not only be concerned in experimental taxonomy with determining genotypes, but also with the way that particular phenotypes may be selected. Given a range of expression of a particular genotype, only certain parts of that range will be selected in particular areas; this was well shown by Dr. Cook's paper on Batrachian Ranunculi. The problems of the taxonomic recognition of plasticity have also not been adequately considered.

Other points of importance which arose out of the papers were the effects of changes in the breeding system from outbreeding to inbreeding, the lack of synchronization of karyotype evolution with morphological and other genic evolution, as in Lathyrus, and the polytopic origin of taxa, such as had been suggested in the water buttereups and in Melampyrum. The question of long-distance dispersal in Clarkia was raised, and a discussion ensued, in which Dr. Gillet, Dr. Jones and Prof. Valentine took part. There was also a brisk exchange of views on the likelihood of the polytopic origin of species, especially in polyploid groups.

V. H. HeYwoon

D. H. Valentine

\section{FOOD TECHNOLOGY IN GHANA}

$T$ O many people nutrition means no more than the study of foods and their use by the living body. But with increasing evidence of widespread malnutrition throughout the world, and of a deteriorating situation in regard to world population and food supplies, much emphasis needs to be placed on the importance of work outside the laboratory on problems associated with providing people everywhere with an adequate diet. In many parts of the world. an immediate problem is a means of conveying foods from one place to another. For example, fruit, the sale of which provides a livelihood for some people, may be rotting on the trees because there are no roads on which it can be transported to other people who might benofit by addition of fruit to their diet. Sometimes roads exist, but mechanical transport is inadequate or excessively costly. Lack of adequate means of distribution may seriously limit the use of fish, and while many people suffer the effects of protein malnutrition, fishermen not far away suffer economic disaster because they cannot get rid of harvest gluts. Not only are roads and mechanical transport involved in the distribution of foods but in addition a means of preservation through cooling, drying or other means.

Ghana is a country where transportation and preservation of foods are of great importance. Owing to the geographical features of the country adequate diets can only be ensured when there is a free exchange of foods grown in the north with those grown in the south. The Government of Ghana has wisely taken steps to deal with nutritional problems, and has included food technology in its programme. The Government has called on the World Health and the Food and Agriculture Organizations for assistance in developing a public health nutrition programme; Dr. Francis Aylward, as Food and Agriculture Organization consultant (see also p. 20 of this issue), has recently examined problems of food supplies and nutrition in Ghana and has submitted a report on this subject*.

Dr. Aylward's report is a most useful one, not only for those interested in Ghana, but for many others

* Report to the Government of Ghana on Foods and Nutrition. By Francis Aylward. ETAP Rep. No, 1449. (Food and Agriculture
Organization of the United Nations, Rome, 1961.) 